\title{
Photodynamic Therapy for the Treatment of Glioblastoma
}

\author{
Samuel W. Cramer and Clark C. Chen* \\ Department of Neurosurgery, University of Minnesota, Minneapolis, MN, United States
}

Glioblastoma is the most common form of adult brain cancer and remains one of the deadliest of human cancers. The current standard-of-care involves maximal tumor resection followed by treatment with concurrent radiation therapy and the chemotherapy temozolomide. Recurrence after this therapy is nearly universal within 2 years of diagnosis. Notably, $>80 \%$ of recurrence is found in the region adjacent to the resection cavity. The need for improved local control in this region, thus remains unmet. The FDA approval of 5-aminolevulinic acid (5-ALA) for fluorescence guided glioblastoma resection renewed interests in leveraging this agent as a means to administer photodynamic therapy (PDT). Here we review the general principles of PDT as well as the available literature on PDT as a glioblastoma therapeutic platform.

Keywords: brain tumor, photodynamic therapy (PDT), glioblastoma multiforme (GBM), tumor-targeting, neurosurgery

OPEN ACCESS

Edited by:

Eberval Figueiredo,

University of São Paulo, Brazil

Reviewed by:

Konstantin Slavin,

University of Illinois at Chicago,

United States

Mario Ganau,

University of Trieste, Italy

*Correspondence:

Clark C. Chen

ccchen@umn.edu

Specialty section:

This article was submitted to

Neurosurgery,

a section of the journal

Frontiers in Surgery

Received: 26 September 2019 Accepted: 23 December 2019

Published: 21 January 2020

Citation:

Cramer SW and Chen CC (2020) Photodynamic Therapy for the

Treatment of Glioblastoma.

Front. Surg. 6:81

doi: 10.3389/fsurg.2019.00081

\section{INTRODUCTION}

Glioblastoma is a malignant central nervous system (CNS) neoplasm with histologic features resembling astrocytic cells. It is the most common form of primary brain cancer, with an incidence of 3.19 per 100,000 people in the United States (1). Glioblastomas are aggressive and infiltrative, with microscopic extension into normal brain parenchyma $(2,3)$. Invading tumor cells exhibit characteristic migratory patterns, including spread beneath the pial margin (subpial spread), along neurons (perineuronal spread), along cerebrovasculature (perivascular satellitosis), or along white matter tracts (intrafascicular spread) (4). Microscopic, infiltrating cells are found centimeters from the margin of the visible tumor mass (5). As such, surgical resection is not curative. The current standard-of-care involves maximal, safe surgical resection followed by concurrent chemotherapy (temozolomide) and fractionated radiotherapy (FRT) (6-9). The overall prognosis for glioblastoma patients is poor, with reported median survival of 14.6 months (7), and tumor recurrence near universal.

The observation that $>80.0 \%$ of the recurrences are located adjacent to the resection cavity suggests utility for therapeutic platforms targeting this region (10-13). The recent United States Food and Drug Administration (FDA) approval of 5-aminolevulinic acid (5-ALA) for fluorescence guided resection (FGR) of tumors renewed interests in leveraging this agent as a means to administer photodynamic therapy (PDT). In principle PDT to the resection cavity can minimize the risk of local recurrence. In this article, we will review the current state of the literature as it pertains to PDT as a glioblastoma therapeutic platform.

\section{METHODS}

The goal of this article is to provide a current state of the art review of photodynamic therapies for the treatment of glioblastoma. To this end, we aim to provide an overview of the 
development of photodynamic therapy for glioblastoma, describe the physical mechanism of the therapeutic approach, describe known interactions between PDT and pharmacological treatments, as well as predict future developments in this field. Therefore, a comprehensive literature search was performed in PubMed (MEDLINE) using MeSH terms "photodynamic therapy gliomas" which resulted in 480 articles. The type of publications considered included clinical and pre-clinical trials, systematic reviews and case series. Relevant publications were then selected based upon validated academic metrics including journal impact factor and i10 factor.

\section{Principle of Photodynamic Therapy (PDT)}

PDT involves photo-activation of a photosensitizer molecule that is selectively incorporated into neoplastic cells. Photoirradiation activates the photosensitizer by transfer of energy to the sensitizer resulting in excitation of molecular oxygen to a singlet or triplet state. In the singlet state the energy is converted to heat (internal conversion) or is emitted as light (fluorescence). In the triplet state, the energy generates reactive oxygen species (ROS) necessary to induce cell death (Figure 1). ROS rapidly react with macromolecules containing unsaturated double bonds, including proteins, unsaturated fatty acids and cholesterols. These reactions damage the membranes of intracellular organelles, such as mitochondria, lysosomes, and the endoplasmic reticulum (8), ultimately triggering necrosis, apoptosis, local ischemia (due to occlusion of neoplastic vessels) as well as subsequent immunological reactions (14).

Singlet oxygen diffuses over short distances (i.e., $\sim 0.02$ $1.00 \mu \mathrm{m}$ ) and has a limited lifespan (i.e., $\sim 0.04-4.0 \mu \mathrm{s}$ ) contributing to local tumor ablation while minimizing risk of damage to adjacent normal tissue (15). The type of photosensitizer and photo-activation determines the specific intracellular components affected as well as the degree and type of damage incurred by those components.

Like ionizing radiation, the cytotoxic effects of PDT requires the presence of molecular oxygen. Thus, the degree of oxygenation with the tumor microenvironment is a key determinant of PDT's tumoricidal activity. In this context, PDT is often delivered through multi-session treatment in order to facilitate re-oxygenation between treatments $(16,17)$. Preclinical and clinical trials of PDT performed in combination with hyperbaric oxygen demonstrate improved tumoricidal activity (18).

Though both radiation and PDT require molecular oxygen for their respective anti-neoplastic activities, their modes of action fundamentally differ. The available data suggest that ionizing radiation triggers cell death through induction of DNA damage (19). In contrast, the predominant model of cytotoxicity by PDT involves damage of cell membranes, proteins, and organelles (20). As such, PDT potentially synergizes with DNA

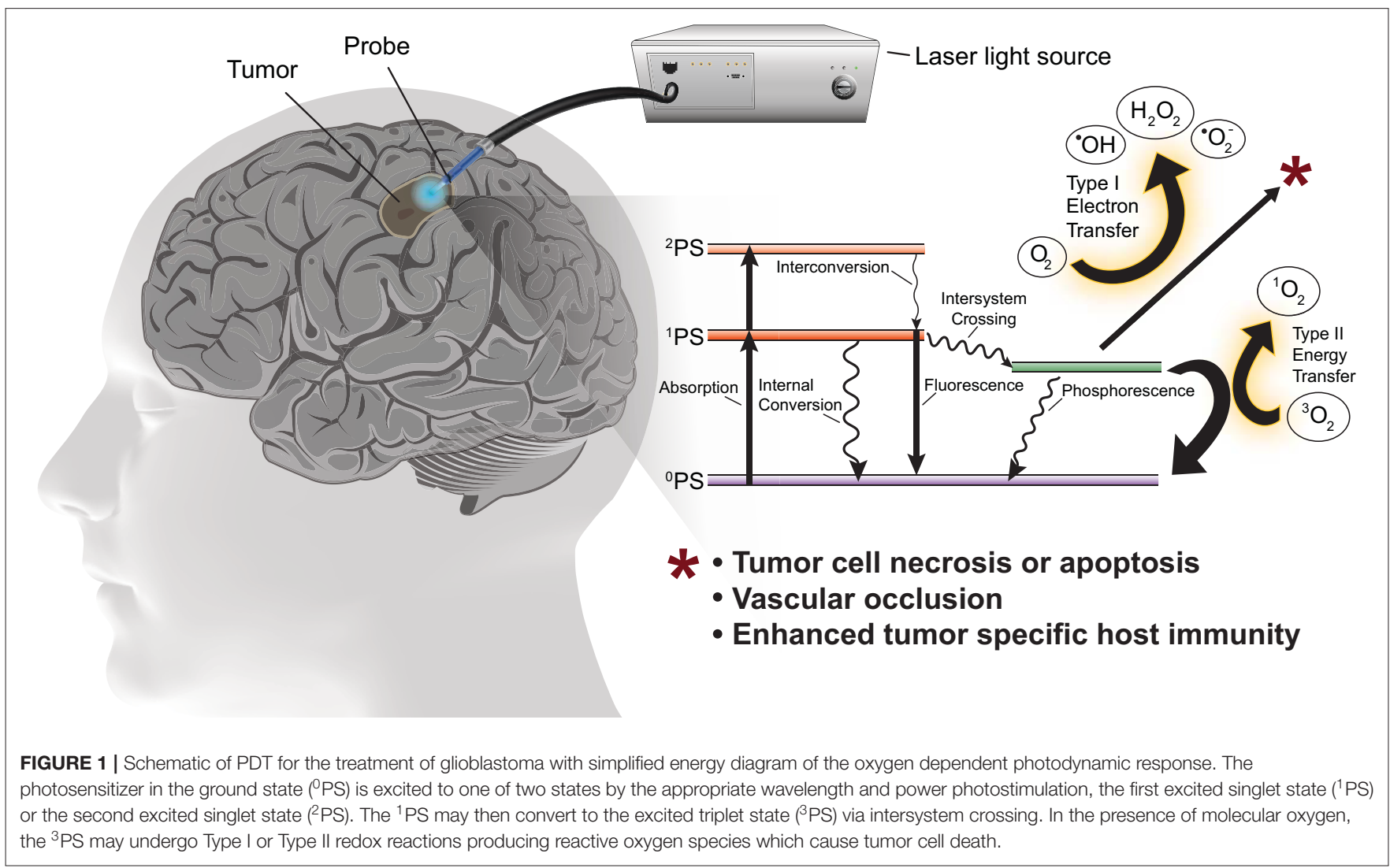


damaging agents routinely used as standard-of-care treatment for glioblastoma (21).

\section{Photo-Activation}

The light source may be incoherent or coherent (i.e., laser). The efficacy of PDT is not affected by the coherence of the light source. The emission wavelength of the light source is adjusted to the absorption spectrum of the photosensitizer. Photo-irradiation with longer wavelength light is preferred because it penetrates more deeply and delivers sufficiently energetic photons to activate the photosensitizer. Given the excitation peaks of clinically available photosensitizers and the limitations of photon propagation through biological tissues, PDT generally utilizes wavelengths between $\sim 400$ and $900 \mathrm{~nm}$, with an optimal window of $600-800 \mathrm{~nm}$ (15). PDT stimulation may be applied in a continuous or pulsed fashion (14), with consideration that pulsed delivery may facilitate tumor reoxygenation between pulses.

\section{First, Second, and Third Generation Photosensitizers}

First-generation photosensitizer molecules consist of naturally occurring porphyrins, including hematoporphyrin (Table 1). These compounds have a strong absorption around $400 \mathrm{~nm}$ but have limited excitation absorption at longer wavelengths of light (22). $\mathrm{HpD}$ is an example of a first generation photosensitizer. It consists of a proprietary combination of monomers, dimers and oligomers derived from hematoporphyrin (23). $\mathrm{HpD}$ is an inefficient producer of singlet oxygen requiring extended photo-stimulation to achieve adequate therapeutic effect (23).

Second-generation photosensitizers were developed to overcome the inherent limitations of first-generation sensitizers. They are usually activated by wavelengths $>600 \mathrm{~nm}$ and are more potent in generating singlet oxygen. Chlorins (talaporfin sodium and temoporfin) and 5-Aminolevulinic acid (5-ALA) are examples of second-generation photosensitizers (15).

Talaporfin sodium and temoporfin are clinically used to treat dermatologic diseases. Talaporfin is water soluble and administered intravenously. As such, it is quickly cleared from the body. Talaporfin is activated by $664 \mathrm{~nm}$ light $(23,24)$.
Temoporfin is the most potent of the clinically available photosensitizers (activated by $652 \mathrm{~nm}$ photostimulation). Temoporfin is generally well-tolerated but does confer photosensitivity for up to 6 weeks post-administration.

Among the commercially available photosensitizers, 5-ALA is commonly utilized (25). The clinical utility is driven by oral bioavailability and a highly favorable safety profile. Pertaining to glioblastomas, 5-ALA exhibits high selectivity in terms of preferential accumulation in malignant gliomas (15). 5-ALA is the first compound in the synthesis of porphyrin, a component required for heme synthesis. Porphyrins are assembled into porphobilinogen, which is converted to protoporphyrin IX (PpIX) by porphobilinogen deaminase. The expression of this deaminase is elevated in glioblastomas, resulting in increased synthesis of PpIX. PpIX is normally converted to heme by the enzyme ferrochelatase (26). Decreased expression of ferrochelatase in glioblastoma arrests this conversion, further augmenting the accumulation of PpIX in glioblastomas (15).

PpIX absorbs blue light $(404 \mathrm{~nm})$ and emits fluorescence in the red spectrum $(635 \mathrm{~nm})$. When excited by $635 \mathrm{~nm}$ light, PpIX generates triplet oxygen and produces cytotoxicity as a photosensitizer (27). Of note, there is significant inter-tumoral heterogeneity in PpIX concentration after 5-ALA administration (25). The molecular underpinning of this variation remains poorly understood though may involve inter-tumoral expression differences in ATP-binding cassette transporters (28).

Third generation photosensitizers are characterized by enhanced tumor cell selectivity achieved through the conjugation of modifiers including nanoparticles and antibodies $(15,23)$. Development of third generation photosensitizers has also emphasized the design of prodrugs that are only activated by neoplastic cells. The goal of rational design of third generation photosensitizers is to reduce off target effects while optimizing pharmacokinetics and excitation-absorption properties to maximize the effective PDT window while minimizing side-effects. At this time, no third generation photosensitizers are approved for PDT in humans.

\section{Blood-Brain Barrier}

In the normal brain, endothelial cells exhibit morphological specializations including the expression of tight junctions that

TABLE 1 | Properties of clinically relevant photosensitizers.

\begin{tabular}{|c|c|c|c|c|c|}
\hline Photosensitizer & Trade name(s) & $\begin{array}{c}\text { Excitation } \\
\text { wavelength(s) }\end{array}$ & $\begin{array}{l}\text { Treatment } \\
\text { window }^{\mathrm{a}}\end{array}$ & $\begin{array}{l}\text { Clearance } \\
\text { time }\end{array}$ & Side effects \\
\hline Talaporfin sodium & $\begin{array}{l}\text { Laserphyrin, Aptocine }{ }^{T M} \text {, } \\
\text { Litx }^{T M}, \text { LS11, Photolon }\end{array}$ & 664 & $2-4 h$ & 15 days & Skin sensitization for 2 weeks \\
\hline $\mathrm{HpD}$ & Photofrin $^{\circledR}$, Photogem ${ }^{\circledR}$ & $408,510,630^{b}$ & $24-48 h$ & 4-6 weeks & Skin sensitization for several weeks \\
\hline $\begin{array}{l}\text { 5-ALA } \\
(\mathrm{PplX})\end{array}$ & Levulan $^{\circledR}$ & $410,510,635^{b}$ & $4-8 h$ & 2 days & $\begin{array}{l}\text { Skin sensitization for few days, nausea, elevated } \\
\text { liver enzymes, anemia, }\end{array}$ \\
\hline Porfimer sodium & Photofrin $\|^{\circledR}$ & 630 & $48-150 h$ & 4-6 weeks & Skin sensitization for several weeks \\
\hline BOPP & $\mathrm{n} / \mathrm{a}$ & 630 & $24 \mathrm{~h}$ & 4-6 weeks & Skin sensitization for several weeks, thrombopenia \\
\hline Temoporfin & Foscan $^{\circledR}$ & 652 & 4 days & 2-6 weeks & Skin sensitization for several weeks \\
\hline
\end{tabular}

a Latency after drug administration and accumulation of photosensitizer in the tumor.

${ }^{b}$ Optimal excitation wavelength for clinical application.

$H p D$, Hematoporphyrin derivative; BOPP, Boronated porphyrin. 
contribute to the formation of the blood-brain barrier (BBB). There is no active transport system for 5-ALA across the BBB. As such, there is little spontaneous diffusion of 5-ALA into normal brain tissue (25). Break-down in the BBB which frequently occurs in the glioblastoma microenvironment facilitates diffusion of 5-ALA into the tumor mass. In this context, 5-ALA guided surgical resection facilitates removal of the contrast enhancement, which is typically observed in these regions of BBB breakdown.

Whether 5-ALA is a true proxy for tumor mass or simply the region of $\mathrm{BBB}$ breakdown remains an open question. The therapeutic window for 5-ALA mediated PDT depends on the extent that PpIX is preferentially accumulated in the glioblastoma cell relative to the cellular constituents of the tumor microenvironment (29).

\section{Medications That May Affect PDT for Glioblastoma}

Glioblastoma patients are commonly prescribed anti-epileptic drugs (AEDs, such as phenytoin and levetiracetam) as well as corticosteroid therapy. There are pre-clinical data that suggests these drugs interact with 5-ALA metabolism. In preclinical investigation, phenytoin administration after 5-ALA infusion suppressed PpIX synthesis by $31.0 \%$ (30). In contrast, levetiracetam did not affect PpIX synthesis or the response to PDT (30).

The interaction between corticosteroid and PpIX synthesis is more complex. PpIX production in response to 5-ALA was reduced by dexamethasone administration. However, the cellular retention of PpIX retention was increased (30). The complexity is further layered in the observation that corticosteroid administration reduced $\mathrm{BBB}$ permeability, which may hinder uptake of 5-ALA (15). Pre-clinical studies suggest that this effect is most prominent for dexamethasone (a commonly used corticosteroid in glioblastoma patients) with doses exceeding $12 \mathrm{mg}$ per day (31).

Additionally, other FDA approved medications increase PpIX accumulation in tumor cells, including iron chelators (deferoxamine and deferiprone), vitamin D, ciprofloxacin, 5-fluorouracil, and febuxostat. Combination of these drugs has been proposed as a means to augment efficacy of 5-ALA in PDT (32).

\section{CLINICAL APPLICATIONS}

Infiltrating glioblastoma cells can be found $4.0 \mathrm{~cm}$ beyond the border of radiologically or histologically identifiable tumor lesions (33). Infiltrating tumor growth and extent of resection is difficult to assess intraoperatively and infiltrative tumor cells are always left behind when using traditional surgical and imaging approaches. Therefore, a method that affords the visual identification of neoplastic tissue and the simultaneous ability to selectively destroy that tissue would likely improve the success of glioblastoma resection. The joint clinical application of fluorescence guided surgery (FGS) and PDT confers the ability to both visualize tumor cells and selectively destroy them.

\section{Interstitial PDT}

Interstitial PDT (iPDT) is applied via the stereotactic insertion of fiber optic cable(s) into the tumor to deliver photostimulation to the tumor mass after the patient has been administered a photosensitizer (25). The application of iPDT is similar to laser interstitial thermal therapy (LITT) for the treatment of glioblastoma as both are minimally invasive stereotactic techniques, however, iPDT has the added benefit of selective neoplastic cell targeting. Several technical considerations are unique to iPDT. For example, selecting a light diffuser with the appropriate geometry to apply optimal photostimulation to the target tumor, determining the optimal number of diffusers to insert into the tumor to maximize therapy while minimizing the harm associated with insertion of the diffuser through normal brain tissue and, finally, proper selection of tumors of the appropriate size, anatomic location, and geometry to maximize the safety and efficacy of iPDT.

A challenge of iPDT is the even delivery of photostimulation to achieve adequate fluence over a maximal volume of tumor without causing thermal injury to the normal brain tissue. Modeling experiments have examined light delivery and determined the optimal geometry of light guides for the delivery of iPDT. Cylindrical light diffusers have a larger emitting surface area with a lower fluence rate at the tissue/light emitter interface than flat cleaved fibers (34). Therefore, light delivery via cylindrical diffuser improves photon distribution with a reduced sensitivity to local tissue absorption variability thereby distributing photostimulation over a greater tissue volume than flat, cleaved fibers. However, the light fluence drops off more rapidly from the flat fiber which is useful when treating a tumor in close proximity to eloquent brain tissue. Therefore, the geometry of the light diffuser as well as the total number of diffusers needed to safely treat a tumor are factors to consider preoperatively in order to achieve optimal iPDT.

The dose of light delivered during PDT is another important consideration. A dosimetry model was developed which is specific to 5-ALA but the underlying principle must be considered for iPDT performed with any photosensitizer. To achieve the maximal therapeutic effect of PDT, the goal is to achieve "advanced photobleaching" (based on an established dosimetry model of the same name) of the photosensitizer. Advanced photobleaching is defined as the fluence rate at which causes $\geq 95 \%$ photobleaching of photosensitizer and is associated with better outcomes $(35,36)$. In the case of 5 -ALA mediated PDT, simulations suggest advanced photobleaching is achieved to a distance of $\sim 4 \mathrm{~mm}$ from the surface of a light diffuser emitting a power of $200 \mathrm{~mW} / \mathrm{cm}$ for $1 \mathrm{~h}$. Based upon the estimated volume of tissue affected by photo-irradiation, the optimal interfiber distance of the photo diffusers for iPDT is $\sim 10 \mathrm{~mm}$ and maximum power of photostimulation should not exceed 200 $\mathrm{mW} / \mathrm{cm}$ as the threshold at which the risk of increasing tissue temperatures $>48^{\circ} \mathrm{C}$ (the threshold at which thermal side-effects become a factor) increases significantly $(25,37)$.

Software for optimization of iPDT delivery has been in development for several decades $(31,36)$. One approach utilizes the co-registration of contrasted magnetic resonance imaging and positron emission tomography imaging with stereotactic 
computed tomography images to allow virtual trajectory planning and positioning of light diffusers within tumors (37). The goal is to virtually plan the implantation of the optimal number of light diffusers for tumor ablation without causing injury to the adjacent vasculature or traversing eloquent cortex.

\section{Post-resection PDT}

After maximal safe tumor resection, PDT may be applied to the resection cavity in the operating room or during post-operative recovery. Cavitary PDT is commonly applied by placing a balloon filled with diffusing liquid (typically a lipid suspension) coupled to a fiber optic guide and an external light source into the intracranial resection cavity. After tumor resection, the balloon is positioned in the cavity and inflated to conform with the geometry of the cavity without causing excessive compression of surrounding brain tissue. In one photostimulation paradigm utilizing the diffuser balloon, total treatment time was derived from the volume of the diffusing media in the balloon and applied in five fractions to the tumor. Between photo-irradiation fractions, $2.0 \mathrm{~min}$ pauses are applied allowing brain tissue reoxygenation. All photostimulation fractions are delivered in the operating room. This is the approach being utilized in the Intraoperative Photodynamic Therapy of glioblastoma (INDYGO) clinical trial which is currently ongoing (17).

Another method for cavitary PDT is to apply fractions of photostimulation out of the operating room during the postoperative recovery period. After FGS, a balloon diffuser is placed in the resection cavity and inflated with a radio-opaque lipid emulsion until the resection cavity is filled. Fluoroscopy is used to verify balloon inflation and later complete deflation, prior to removal. The first PDT treatment is applied in the recovery area with daily PDT treatments delivered subsequently at the bedside for a total of 5 treatments. A key consideration for applying PDT over a prolonged time period is the effective half-life of the photosensitizer (in this example porfimer sodium was used). After the total number of treatments are delivered, the balloon diffuser is deflated and removed at the bedside $(38,39)$.

\section{CLINICAL OUTCOMES OF PDT TREATED GLIOBLASTOMAS}

Outcomes after PDT in glioblastoma patients are generally favorable compared to historical data, however, the quality of the studies is limited by the lack of randomized controlled trials. The Royal Melbourne Hospital group has the most extensive clinical experience with PDT for gliomas with a series of more than 350 patients and report overall survival rates of those with newly diagnosed and recurrent glioblastomas of 28.0 and $40.0 \%$, at 2 years and 22.0 and $34.0 \%$ at 5 years, respectively, an improvement compared to historical controls. Similarly, a metaanalysis of more than 1,000 patients enrolled in observational studies of PDT for high-grade gliomas reported median survival of newly diagnosed and recurrent glioblastomas of 16.1 and 10.3 months, respectively (40). A summary of a summary of clinical trials evaluating PDT for the treatment of glioblastomas is found in Table 2.

\section{HpD Mediated PDT for Glioblastoma}

An early study evaluating the efficacy of $\mathrm{HpD}$ mediated PDT enrolled 18 glioblastoma patients. $\mathrm{HpD}$ was administered via direct arterial puncture during preoperative angiogram, IV or directly into the tumor during craniotomy for tumor resection. Cavitary PDT was applied intraoperatively after tumor resection. Patients were brought back to the operating room 3 days later for redo-craniotomy and administered another round of PDT. At publication, six patients with primary glioblastomas were surviving at 22.0 months (43).

The effects of $\mathrm{HpD}$ or porfimer sodium mediated PDT on glioblastomas was evaluated in 17 patients. Patients were administered the photosensitizer $18-24 \mathrm{~h}$ prior to undergoing maximal tumor resection and intraoperative, cavitary PDT was applied via an inflatable balloon diffuser. For glioblastoma patients that died during follow-up, mean survival was 6.3 months post-PDT (46).

$\mathrm{HpD}$ concentration in tumor tissue compared to survival after PDT was evaluated in 58 glioblastoma patients. Patients underwent maximal safe tumor resection, then intraoperative, cavitary PDT was administered by filling the resection cavity with a continuously circulating lipid emulsion while photostimulation was applied. There was a strong association between $\mathrm{HpD}$ uptake and survival among treated patients (Hazard Ratio $=0.26$, $p=0.001$ ) and the median overall survival for glioblastoma patients after PDT was 24.0 months (57). A similar study evaluating $\mathrm{HpD}$ mediated PDT for high grade gliomas including 78 glioblastoma patients was performed. Patients underwent maximal safe tumor resection followed by intra-operative photoirradiation. The median overall survival for glioblastoma patients treated with PDT was 14.3 months (58).

\section{Porfimer Sodium Mediated PDT for Glioblastoma}

A case series reports the efficacy of porfimer sodium mediated PDT for newly diagnosed and recurrent glioblastomas in 49 patients. After the maximal tumor resection, either a balloon diffuser was placed in the resection cavity or the resection cavity itself was filled with a continuous infusion of lipid emulsion and photo-irradiation was applied. The median survival of glioblastoma patients was 30 weeks, with 1 - and 2-years actuarial survival of 22.0 and $2.0 \%$, respectively (48).

A small study was conducted to evaluate porfimer sodium or temoporfin mediated PDT for malignant primary brain tumors, including 20 glioblastoma patients. Patients underwent tumor resection followed by photo-irradiation to the resection cavity. Light was delivered with a $630 \mathrm{~nm}$ laser with a fluence of $75 \mathrm{~J} / \mathrm{cm}^{2}$ in porfimer sodium patients and at $652 \mathrm{~nm}$ with a fluence of $20 \mathrm{~J} / \mathrm{cm}^{2}$ in the temoporfin patients. A continuous infusion of lipid emulsion was applied to the resection cavity during photoirradiation to minimize the risk of thermal injury to brain tissue. Post-operatively, patients were kept in a unique ICU room with no exposure to sun-light. Sunlight was avoided for 4 weeks (porfimer sodium) or 2 weeks (temoporfin). Patients received standard temozolomide chemotherapy and FRT postoperatively. Median OS for these patients was 17 months (59). 
TABLE 2 | Summary of clinical trials using PDT for the treatment of GBM.

\begin{tabular}{|c|c|c|c|c|c|c|c|}
\hline \multirow[t]{2}{*}{ References } & \multicolumn{2}{|c|}{$\begin{array}{l}\text { Number of } \\
\text { patients }\end{array}$} & \multicolumn{2}{|c|}{ Photosensitizer } & \multicolumn{2}{|c|}{ Photo-irradiation } & \multirow[t]{2}{*}{$\begin{array}{l}\text { Median overall } \\
\text { survival (mo) }\end{array}$} \\
\hline & $\begin{array}{l}\text { New } \\
\text { GBM }\end{array}$ & rGBM & Drug & $\begin{array}{l}\text { Dose, route of } \\
\text { administration }\end{array}$ & $\begin{array}{l}\text { Wavelength, } \\
\mathrm{nm}\end{array}$ & $\begin{array}{l}\text { Energy density } \\
\left(\mathrm{J} / \mathrm{cm}^{2}\right)\end{array}$ & \\
\hline Stupp et al. (6) & 287 & & $\mathrm{n} / \mathrm{a}$ & $\mathrm{n} / \mathrm{a}$ & $\mathrm{n} / \mathrm{a}$ & $\mathrm{n} / \mathrm{a}$ & $14.6^{\mathrm{C}}$ newly diagnosed \\
\hline Akimoto et al. (41) & 6 & 8 & Talaporfin sodium & $40 \mathrm{mg} / \mathrm{m}^{2}, \mathrm{IV}$ & 664 & 27 & $\mathrm{n} / \mathrm{a}$ \\
\hline Beck et al. $(37)^{\mathrm{a}}$ & & 10 & 5-ALA & $20 \mathrm{mg} / \mathrm{kg}, \mathrm{PO}$ & 633 & 100 & 15 rGBM \\
\hline Eljamel et al. (39) & 13 & & $\begin{array}{l}\text { 5-ALA and } \\
\text { Porfimer sodium }\end{array}$ & $\begin{array}{l}2 \mathrm{mg} / \mathrm{kg} \text { Photofrin IV; } \\
20 \mathrm{mg} / \mathrm{kg} \text { 5-ALA, PO }\end{array}$ & 630 & 100 & $13.2^{d}$ newly diagnosed \\
\hline Johansson et al. (36)a & 1 & 4 & 5-ALA & $20-30 \mathrm{mg} / \mathrm{kg}$ & 635 & $720 \mathrm{~J} / \mathrm{cm}$ & $\mathrm{n} / \mathrm{a}$ \\
\hline Kaye et al. (42) & 13 & 6 & $\mathrm{HpD}$ & $5 \mathrm{mg} / \mathrm{kg}, \mathrm{IV}$ & 630 & $\begin{array}{c}70-120 \text { or } \\
120-230 \mathrm{~J} / \mathrm{cm}^{2}\end{array}$ & $\mathrm{n} / \mathrm{a}$ \\
\hline Kostron et al. (43) & 18 & & HpD & 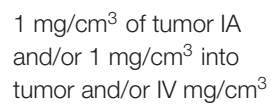 & 630 & $40-120$ & $\mathrm{n} / \mathrm{a}$ \\
\hline Kostron et al. (44) & & 26 & Temoporfin & $0.15 \mathrm{mg} / \mathrm{kg}, \mathrm{IV}$ & 652 & 20 & 8.5 rGBM \\
\hline McCulloch et al. (45) & 9 & & HpD & $5 \mathrm{mg} / \mathrm{kg}, \mathrm{IV}$ & $627.8^{b}$ & $\mathrm{n} / \mathrm{a}$ & $\mathrm{n} / \mathrm{a}$ \\
\hline Muller and Wilson (46) & 17 & & $\begin{array}{l}\mathrm{HpD} \text { or Porfimer } \\
\text { sodium }\end{array}$ & $1.4-2.7 \mathrm{mg} / \mathrm{kg}, \mathrm{IV}$ & 630 & $8-68$ & $\mathrm{n} / \mathrm{a}$ \\
\hline Muller and Wilson (47) & & 32 & $\begin{array}{l}\text { HpD or Porfimer } \\
\text { sodium }\end{array}$ & $5 \mathrm{mg} / \mathrm{kg}, \mathrm{IV} ; 2 \mathrm{mg} / \mathrm{kg}, \mathrm{IV}$ & 630 & $8-110$ & $\begin{array}{l}7.5 \text { (29.5 from } \\
\text { diagnosis) rGBM }\end{array}$ \\
\hline Muller and Wilson (48) & 12 & 37 & Porfimer sodium & $2 \mathrm{mg} / \mathrm{kg}, \mathrm{IV}$ & $\mathrm{n} / \mathrm{a}$ & 58 (mean) & $\begin{array}{l}8.25 \text { newly diagnosed, } \\
7.25 \text { rGBM }\end{array}$ \\
\hline Muller and Wilson (49) & 11 & & Porfimer sodium & $2 \mathrm{mg} / \mathrm{kg}, \mathrm{IV}$ & 630 & $8-110$ & 9.25 newly diagnosed \\
\hline Muller et al. (50) & & 37 & Porfimer sodium & $2 \mathrm{mg} / \mathrm{kg}, \mathrm{IV}$ & $\mathrm{n} / \mathrm{a}$ & $8-150$ & 7.75 rGBM \\
\hline Muragaki et al. (51) & 13 & & Talaporfin sodium & $40 \mathrm{mg} / \mathrm{m}^{2}, \mathrm{IV}$ & 664 & 27 & 24.8 newly diagnosed \\
\hline Nitta et al. (52) & 30 & & Talaporfin sodium & $40 \mathrm{mg} / \mathrm{m}^{2}, \mathrm{IV}$ & 664 & 27 & 27.4 newly diagnosed \\
\hline Origitano et al. (31) ${ }^{\mathrm{a}}$ & & 8 & Porfimer sodium & $2 \mathrm{mg} / \mathrm{kg}, \mathrm{IV}$ & 630 & $\begin{array}{l}50(100 \mathrm{~J} / \mathrm{cm} \\
\text { interstitial) }\end{array}$ & $\mathrm{n} / \mathrm{a}$ \\
\hline Popovic et al. (53) & 38 & 40 & $\mathrm{HpD}$ & $5 \mathrm{mg} / \mathrm{kg}, \mathrm{IV}$ & 628 & $72-260$ & $\begin{array}{l}24 \text { newly diagnosed, } \\
9 \text { rGBM }\end{array}$ \\
\hline Powers et al. (54) & 2 & & Porfimer sodium & $2 \mathrm{mg} / \mathrm{kg}, \mathrm{IV}$ & 630 & $400 \mathrm{~J} / \mathrm{cm}$ & $\mathrm{n} / \mathrm{a}$ \\
\hline Rosenthal et al. (55) & 7 & 9 & $\begin{array}{l}\text { Boronated } \\
\text { porphyrin }\end{array}$ & $0.25-8.0 \mathrm{mg} / \mathrm{kg}, \mathrm{IV}$ & 630 & $25-100$ & $\begin{array}{l}5 \text { newly diagnosed, } \\
11 \text { rGBM }\end{array}$ \\
\hline Schwartz et al. (56) ${ }^{a}$ & 15 & & 5-ALA & $20-30 \mathrm{mg} / \mathrm{kg}, \mathrm{PO}$ & 633 & $12.960 \mathrm{~J}$ & $\mathrm{n} / \mathrm{a}$ \\
\hline Stylli et al. (57) & 58 & & $\mathrm{HpD}$ & $5 \mathrm{mg} / \mathrm{kg}, \mathrm{IV}$ & $\mathrm{n} / \mathrm{a}^{\mathrm{b}}$ & $\begin{array}{c}240 \mathrm{~J} / \mathrm{cm}^{2} \\
\text { (median) }\end{array}$ & 24 newly diagnosed \\
\hline Stylli et al. (58) & 31 & 55 & $\mathrm{HpD}$ & $5 \mathrm{mg} / \mathrm{kg}, \mathrm{IV}$ & $\mathrm{n} / \mathrm{a}^{\mathrm{b}}$ & $\begin{array}{c}230 \mathrm{~J} / \mathrm{cm}^{2} \\
\text { (median) }\end{array}$ & $\begin{array}{l}14.3 \text { newly diagnosed, } \\
14.9 \text { rGBM }\end{array}$ \\
\hline Vanaclocha et al. (59) & 20 & & $\begin{array}{l}\text { Porfimer sodium } \\
\text { or temoporfin }\end{array}$ & $\begin{array}{l}2 \mathrm{mg} / \mathrm{kg}, \mathrm{IV} ; 0.15 \mathrm{mg} / \mathrm{kg} \text {, } \\
\mathrm{IV}\end{array}$ & $630 ; 652$ & $20-75$ & 17 newly diagnosed \\
\hline
\end{tabular}

${ }^{a}$ iPDT.

${ }^{b}$ Multiple lasers used.

${ }^{c}$ Reference survival time for newly diagnosed GBM.

dMean.

rGBM, recurrent GBM; $H p D$, hematoporphyrin derivative.

A phase II study evaluated porfimer sodium mediated PDT for newly diagnosed and recurrent supratentorial gliomas including 37 recurrent and 11 newly diagnosed glioblastomas. Subjects enrolled in the study underwent tumor resection followed by intraoperative placement of expandable balloon irradiator filled with a light dispersion medium for photo-irradiation $(49,50)$. Those with recurrent glioblastomas who had failed prior surgical resection and FRT (with or without chemotherapy) underwent PDT while patients with newly diagnosed tumors underwent surgical resection with intraoperative PDT. The median survival for newly diagnosed glioblastoma patients was 7.75 months while those with recurrent glioblastomas had a median survival of 9.25 months.

The application of PDT as treatment for glioblastomas was first evaluated in a randomized, controlled trial by Muller and Willson $(40,48)$. The treatment arm enrolled 43 patients who underwent glioblastoma resection followed by porfimer sodium mediated PDT and was compared to 34 patients who underwent tumor resection alone. Post-operative FRT was administered to all patients. Median survival was 11.0 months (95\% CI 6.0-14.0 
months) in the treatment group compared to 8.0 months $(95 \%$ CI 3.0-10.0 months) in the control group. A $38.0 \%$ increase in median survival with PDT as well as $>6.0$-months survival rate in the treatment group were statistically significant, but Kaplan-Meier curves crossed over at 15 months (14, 40, 48).

Eljamel et al. conducted a single-center, randomized controlled phase III trial to evaluate porfimer sodium mediated PDT after 5-ALA FGS for newly diagnosed glioblastomas. In the study, 13 patients underwent FGS for glioblastoma resection followed by intracavitary placement of a balloon diffuser to provide repetitive PDT (1 session per day, $100 \mathrm{~J} / \mathrm{cm}^{2}$ applied per session) for 5 days during the post-operative period. The control arm underwent FGS for tumor resection without PDT. Post-operatively, all patients underwent FRT and were followed clinically and radiographically every 3 months until death. There was no statistically significant difference in the frequency of adjuvant and salvage treatments between the two cohorts. The mean survival of patients in the PDT and surgery only groups was 52.8 weeks (95\% CI 40.0-65.0 weeks) and 24.2 weeks (95\% CI 18.0-30.0 weeks), respectively ( $p<0.001)$. Despite an overall worse functional status in the study group prior to FGS and PDT, their functional status improved to a much higher level post-operatively compared to the surgery only group. There was no residual tumor on discharge in 10 out of 13 patients in the PDT group and in 4 out of 14 patients in the surgery only group. There was also no difference between the groups in the average length of stay in the hospital or in the complication rate.

\section{Talaporfin Sodium Mediated PDT for Glioblastoma}

Talaporfin sodium accumulates selectively in high grade gliomas and is useful for intraoperative photodiagnosis of malignant brain tumors (60). Furthermore, several small case series report the safety and efficacy of talaporfin sodium mediated PDT as glioblastoma treatment. Thirty newly diagnosed glioblastoma patients treated with PDT in addition to standard FRT and temozolomide were compared to 164 patients with newly diagnosed glioblastomas who received standard therapy alone. The median survival time was 27.4 months for PDT patients compared to 22.1 months for those receiving standard therapy (52).

Another case series reported a median survival of 26.0 months (with one patient surviving $>38.0$ months) for four newly diagnosed glioblastoma patients treated with maximal safe tumor resection followed by talaporfin sodium mediated PDT while six patients with recurrent glioblastomas who underwent the same treatment had a median survival of 8.5 months (41). Muragaki et al. report their experience with talaporfin sodium PDT for the treatment of newly diagnosed or recurrent malignant primary brain tumors (including 13 glioblastoma patients). Patients underwent craniotomy and tumor resection followed by intraoperative cavitary PDT. The photostimulation was targeted to regions with high risk of tumor recurrence including the genu of the corpus callosum. In total, 1-3 regions within the resection cavity were targeted with photo-irradiated. All patients with newly diagnosed glioblastomas underwent FRT and adjuvant chemotherapy with temozolomide in addition to PDT. The median overall survival for patients with newly diagnosed glioblastomas was of 24.8 months with a median progression free survival of 12.0 months (51).

\section{5-ALA Mediated PDT for Glioblastoma}

Two series report their experience with 5-ALA mediated iPDT for malignant gliomas. In a pilot study, the efficacy of 5-ALA mediated iPDT for small (maximum diameter $<3 \mathrm{~cm}$ ), circumscribed recurrent malignant gliomas was evaluated in 10 patients. Based upon 3-D photoirradiation simulations during preoperative planning, 4-6 fiber diffusers were stereotactically placed per patient to achieve complete photo-irradiation of the tumors. The 1-year survival rate was $60.0 \%$ with a median survival of 15.0 months (37). A similar series in 15 patients with small newly diagnosed $(<4 \mathrm{~cm})$ and unresectable glioblastomas who underwent 5-ALA iPDT and were compared to glioblastoma patients $(n=112)$ who underwent complete tumor resection alone. All patients received standard radiotherapy and temozolomide. The iPDT group demonstrated significantly longer median progression free survival of 16.0 vs. 10.2 months and a 3 -years survival of 56.0 vs. $21.0 \%$ (56). Of note, 6 of the 15 patients in the iPDT group experienced progression free survival $>30$ months.

\section{Boronated Porphyrin and Temoporfin Mediated PDT for Glioblastoma}

A phase I trial evaluated the safety of boronated porphyrin (BOPP) for the treatment of high-grade gliomas including seven patients with newly diagnosed and 9 patients with recurrent glioblastomas. The dose of BOPP and photo-irradiation were varied incrementally with the goal of determining the maximum safe doses. The median overall survival for newly diagnosed glioblastomas was 5.0 months and the median overall survival for those with recurrent glioblastomas after PDT was 11.0 months (55).

A non-randomized controlled phase II study evaluated temoporfin mediated PDT in 26 patients with recurrent glioblastomas. Prior to enrollment, all patients had received standard surgical, chemo and radiation therapy. The PDT consisted of FGS (classified as a macroscopically total resection in $75.0 \%$ of cases) followed by the administration of intraoperative PDT. The median survival was 8.5 months, and the 2-years survival rate was $15.0 \%$. The median survival rates for the PDT treated patients was significantly better than the survival in the control group (44).

\section{Efficacy of PDT for Glioblastoma}

Despite sample size limitations and few randomized controlled studies of PDT, the data suggest potential beneficial effect of PDT for improving survival in glioblastoma patients when compared to standard therapy. The extent of PDT's practical application is hindered by the depth of light penetration into brain and tumor tissue with an estimated effective therapeutic spatial window for PDT limited to $\sim 0.75-1.5 \mathrm{~cm}$ from the light source $(16,41$, 61). At this time given the above limitations of light delivery 
and photosensitizer properties, aggressive tumor resection is necessary prior to application of PDT except in the case of very small tumors.

\section{Safety of PDT for the Treatment of Glioblastomas}

Beyond complications associated with brain tumor resection, adverse events uniquely related to PDT include the systemic administration of a photosensitizer, the application of photostimulation and photochemical reactions. Each photosensitizer confers a slightly different safety profile. A risk common to all photosensitizers is retinal and cutaneous photosensitivity which occurs for several days in the case of 5-ALA to up to 6 weeks for temoporfin, during which time exposure to direct sunlight should be avoided (23).

A phase I-II study conducted by Kaye et al. that examined the efficacy of high-dose PDT using the photosensitizer HpD in 23 patients with malignant brain tumors found no evidence of increased cerebral edema nor any other adverse events, including hematological, hepatic and renal dysfunction (42). In another case series of 20 patients, side-effects of $\mathrm{HpD}$ administration included one patient with dermatotoxicity consisting of swelling of the head and hands after sun-exposure despite the application of sun blocking agents, which lasted for 1 week and three patients experienced meningeal symptoms (stiff neck, fever, headache) after direct injection of $\mathrm{HpD}$ into the tumors which lasted for 3 days (43). There was no mortality associated with PDT, however, three patients experienced symptomatic cerebral edema that responded to medical management. Another series reports a cerebral edema incidence of $0.04 \%$ cerebral edema after $\mathrm{HpD}$ PDT (58).

Reports of stereotactic iPDT suggest it is safe when applied to appropriately selected patients. One of the primary considerations is post-iPDT edema. In the experience at Kashiwaba Neurosurgical hospital with porfimer sodium mediated iPDT, cerebral edema was observed post-operatively in $46.0 \%$, though the swelling was mild and did not require therapeutic intervention in $42.0 \%$ of cases (14).

Evaluation of 112 brain tumor patients treated with porfimer sodium mediated PDT yielded adverse events in $25.0 \%$ of cases (48). Among the adverse events were death (2.7\%), postoperative hemorrhage (2.7\%), neurological deficit (6.2\%), deep venous thrombosis (3.6\%), infection (3.6\%), and light sensitivity reactions, such as hand burns, facial erythema, and facial pruritus $3.6 \%$ of patients. The majority of adverse events, however, were surgical and not directly related to photo-irradiation except for light sensitivity (48).

In a series of 365 PDT applications with 5-ALA and porfimer sodium in 150 brain tumor patients, adverse events occurred in $4.7 \%$ of patients (40). Deep venous thrombosis occurred in $2.0 \%$ of patients after administration of porfimer sodium, while no cases were observed after 5-ALA administration. Serious skin photosensitivity reactions developed in $1.3 \%$ of patients after non-adherence to light protection precautions. The photosensitivity reactions were considered avoidable had precautions been taken. Cerebral edema occurred after porfimer sodium mediated PDT in $1.3 \%$ of patients with recurrent tumors requiring intervention. In $0.7 \%$ of patients, there was rupture of the balloon diffuser used for photo-irradiation during PDT or cerebrospinal fluid leak (40).

In another series of 41 patients treated with porfimer sodium or temoporfin PDT, two patients with thalamic tumors died postoperatively due to significant post-treatment cerebral edema (59). Several adverse events were encountered during the trial. First, one scalp burn required plastic surgery with a cutaneous graft for repair. Other cutaneous toxicities were observed including blisters on the forearm and cutaneous erythema. A case of burn injury on the thumbnail from pulse oximeter was observed (59).

In another large case series of 100 patients with primary brain tumors who underwent $\mathrm{HpD}$ or porfimer sodium PDT, the authors report a mortality of $3.0 \%$ and combined serious morbidity-mortality rate of $8.0 \%$ (50). Of note, mean postoperative ICP is significantly higher after $\mathrm{HpD}$ or porfimer sodium mediated PDT compared to control patients (46).

Overall, porfimer sodium PDT has been associated with more adverse events than other photosensitizers, such as 5-ALA. For example, porfimer sodium is associated with increased risk of neurological deficits at a total photo-irradiation dose above $4,000 \mathrm{~J}$ (62). However, the apparent increased risk of adverse events with porfimer sodium mediated PDT compared to the use of other photosensitizers PDT may be due to the larger number of patients treated with porfimer sodium PDT.

There have been no systematic reviews of PDT safety. Overall, the common risks of PDT are retinal and cutaneous photosensitivity after administration of the photosensitizer. However, the risk of photosensitivity reactions are time limited and may be mitigated by avoidance of direct sun-light. The most serious safety risk of PDT is uncontrolled cerebral edema. The exact rate of cerebral edema after PDT is not known since it varies by photosensitizer as well as with the mode of delivery and intensity of photo-stimulation utilized during therapy.

\section{EMERGING TECHNOLOGIES, ADVANCEMENTS IN PDT FOR GLIOBLASTOMAS \\ PDT Mediated Immune Response}

PDT has several unique properties that induce effective antitumor responses, such as apoptosis, autophagy, and necrosis as well as immunogenic cell death (ICD) (8). The unique modes of cell death evoked by PDT are thought to underlie a robust tumorspecific immune response which potentially leads to sustained immune mediated surveillance and suppression of neoplastic cell growth.

A mouse model cured of brain tumor by PDT provided the first evidence for induction of a tumor-specific immune response by resisting subsequent tumor cell re-challenge a tumor-specific manner while immunosuppressed mice did not resist the re-challenge (63). Several years later, the cellular mechanism of the anti-tumor immunity was further elucidated. Among the different modes of PDT induced cell death, ICD is a type of cell death whereby neoplastic cells expose and/or 
release of tumor antigens molecules known as damage associated molecular patterns (DAMPs) $(64,65)$ which activate both innate and adaptive immune responses (66). DAMPs are integral components of cells that are only exposed on the plasma membrane and/or released in response to injury, such as the oxidative damage caused by PDT. DAMPs play a key role in cell mediated immunity by causing the activation and stimulation of antigen processing/presentation by antigen presenting cells (APCs). The activation of APCs causes their migration and proliferation in local lymph nodes where the APCs then present the tumor antigens to $\mathrm{CD} 8^{+} \mathrm{T}$ cells (8). Activated CD8 ${ }^{+} \mathrm{T}$ cells actively surveil the body for neoplastic cells and induce apoptosis whenever tumor cells are encountered, thereby providing longterm tumor control. Therefore, ICD induced by PDT has the potential to stimulate immune activation and surveillance, contributing to long term tumor control is observed in preclinical models $(63,66-69)$.

Overall, the survival benefit of PDT trials for malignant gliomas has been modest, thus providing the rationale for adjuvant therapies, such as further augmentation of the immune response initiated by PDT. There have been few experimental studies exploring the effects of direct PDT mediated immune response on brain tumor growth and to our knowledge no clinical studies to date.

\section{Nanoparticle Photosensitizers}

Nanoparticle technology provides several opportunities to improve upon the delivery, bio-availability, selectivity, and functionality of currently available photosensitizing molecules while reducing side-effects (70-72). Selective drug delivery using nanotechnology is an area of active research that may provide functional tumor cell type specific delivery capabilities as well as provide improved systemic pharmacokinetics of photosensitizer molecules (73-75). For example, nanoparticleconjugated photosensitizers are in development to exploit tumor specific cell surface receptors which would deliver the photosensitizer directly to the tumor cell (76). The goal is to develop nanoparticles that are able to cross the $\mathrm{BBB}$ and selectively enter tumor cells. The availability of a photosensitizer capable of crossing the BBB and selectively entering tumor cells would broaden the spectrum of brain tumor targets to lower grade tumors for PDT as the requisite tumor mediated disruption of the BBB would be eliminated.

Upconverting nanoparticles, nanoparticles that convert multiple incident photons (generally in the infrared range) into an emitted photon (in the visible light range) of higher energy for PDT is an area of active research $(77,78)$. Another shortcoming of clinically available photosensitizers is the peak excitation wavelength necessary for activation requires wavelengths of light that poorly penetrate brain tissue. To address this limitation,

\section{REFERENCES}

1. Tamimi AF, Juweid M. Epidemiology and outcome of glioblastoma. In: De VleeSchouwer S, editor. Glioblastoma. Brisbane, QLD: Codon Publications (2017). p. 143-53. doi: 10.1016/B978-0-323-47660-7.00006-9 nanoparticles are in development that are activated by deeperpenetrating near infrared light which causes the nanoparticles to release photons at the photosensitizer excitation wavelengths (78). The goal is to achieve a higher degree of tumor cell specificity (even in regions with intact $\mathrm{BBB}$ ) while being able to apply PDT at greater distances from the light source and, therefore, over a larger tissue volume than can be achieved using current PDT techniques.

\section{CONCLUSION}

Following on the heels of the recent FDA approval of 5-ALA for fluorescent guided glioblastoma resection, there is emerging interest in leveraging this agent toward administering photodynamic therapy (PDT) to the resection cavity. Review of the available literatures suggests that such PDT can be safely delivered to prevent local tumor recurrence. However, it is difficult to extrapolate the efficacy of the regimen given significant heterogeneity in study design, patient cohort, and PDT agents. This review provides data spanning over 25 years of technological sophistication of PDT, hence overlaps with extension in life expectancy and quality of life parameters conferred to glioblastoma patients by optimization of their multispecialistic care are difficult to evaluate. However, lack of clear efficacy of PDT in overall survival has limited the wide-spread adaption of this technology and implementation as a standard treatment of glioblastoma. Furthermore, technical limitations in light delivery and photosensitizer design have blunted the impact that this technology might have in the treatment of glioblastoma.

The immunological effects of PDT is of particular interest given recent studies demonstrating the importance of these processes in glioblastoma. Further studies of PDT in glioblastoma after stratification of pertinent molecular biomarkers, including isocitrate dehydrogenase mutation status and methyl-guaninemethyl transferase (MGMT) promoter methylation status is warranted. Incorporation of PDT into the current standard-ofcare therapy should be explored in this context. Furthermore, exploration of next generation photosensitizer agents with increased specificity to glioblastoma is equally warranted.

\section{AUTHOR CONTRIBUTIONS}

All authors listed have made a substantial, direct and intellectual contribution to the work, and approved it for publication.

\section{ACKNOWLEDGMENTS}

We thank Alexander Cramer for generating graphics.
2. Claes A, Idema AJ, Wesseling P. Diffuse glioma growth: a guerilla war. Acta Neuropathol. (2007) 114:443-58. doi: 10.1007/s00401-007-0293-7

3. Sahm F, Capper D, Jeibmann A, Habel A, Paulus W, Troost D, et al. Addressing diffuse glioma as a systemic brain disease with single-cell analysis. Arch Neurol. (2012) 69:523-6. doi: 10.1001/archneurol.2011.2910 
4. Scherer HJ. The forms of growth in gliomas and their practical significance. Brain. (1940) 63:1-35. doi: 10.1093/brain/63.1.1

5. Kelly PJ, Daumas-Duport C, Kispert DB, Kall BA, Scheithauer BW, Illig JJ. Imaging-based stereotaxic serial biopsies in untreated intracranial glial neoplasms. J Neurosurg. (1987) 66:865-74. doi: 10.3171/jns.1987.66.6.0865

6. Stupp R, Mason WP, van den Bent MJ, Weller M, Fisher B, Taphoorn MJB, et al. Radiotherapy plus concomitant and adjuvant temozolomide for glioblastoma. N Engl J Med. (2005) 352:987-96. doi: 10.1056/NEJMoa043330

7. Stupp R, Hegi ME, Mason WP, van den Bent MJ, Taphoorn MJB, Janzer RC, et al. Effects of radiotherapy with concomitant and adjuvant temozolomide versus radiotherapy alone on survival in glioblastoma in a randomised phase III study: 5-year analysis of the EORTC-NCIC trial. Lancet Oncol. (2009) 10:459-66. doi: 10.1016/S1470-2045(09)70025-7

8. Hirschberg H, Berg K, Peng Q. Photodynamic therapy mediated immune therapy of brain tumors. Neuroimmunol Neuroinflamm. (2018) 5:27. doi: 10.20517/2347-8659.2018.31

9. Pellerino A, Franchino F, Soffietti R, Rudà R. Overview on current treatment standards in high-grade gliomas. Q J Nucl Med Mol Imaging. (2018) 62:22538. doi: 10.23736/S1824-4785.18.03096-0

10. Petrecca K, Guiot MC, Panet-Raymond V, Souhami L. Failure pattern following complete resection plus radiotherapy and temozolomide is at the resection margin in patients with glioblastoma. J Neurooncol. (2013) 111:1923. doi: 10.1007/s11060-012-0983-4

11. Ganau M, Foroni RI, Gerosa M, Zivelonghi E, Longhi M, Nicolato A. Radiosurgical options in neuro-oncology: a review on current tenets and future opportunities. Part I: therapeutic strategies. Tumori. (2014) 100:459-65. doi: $10.1700 / 1636.17912$

12. Ganau M, Foroni RI, Gerosa M, Ricciardi GK, Longhi M, Nicolato A. Radiosurgical options in neuro-oncology: a review on current tenets and future opportunities. Part II: adjuvant radiobiological tools. Tumori. (2015) 101:57-63. doi: 10.5301/tj.5000215

13. Thon N, Tonn JC, Kreth FW. The surgical perspective in precision treatment of diffuse gliomas. Onco Targets Ther. (2019) 12:1497-508. doi: 10.2147/OTT.S174316

14. Kaneko S, Fujimoto S, Yamaguchi H, Yamauchi T, Yoshimoto T, Tokuda K. Photodynamic therapy of malignant gliomas. Prog Neurol Surg. (2018) 32:1-13. doi: 10.1159/000469675

15. Mahmoudi K, Garvey KL, Bouras A, Cramer G, Stepp H, Jesu Raj JG, et al. 5-Aminolevulinic acid photodynamic therapy for the treatment of high-grade gliomas. J Neurooncol. (2019) 141:595-607. doi: 10.1007/s11060-019-03103-4

16. Bechet D, Mordon SR, Guillemin F, Barberi-Heyob MA. Photodynamic therapy of malignant brain tumours: a complementary approach to conventional therapies. Cancer Treat Rev. (2014) 40:229-41. doi: 10.1016/j.ctrv.2012.07.004

17. Dupont C, Vermandel M, Leroy HA, Quidet M, Lecomte F, Delhem N, et al. INtraoperative photoDYnamic Therapy for GliOblastomas (INDYGO): study protocol for a phase I clinical trial. Neurosurgery. (2019) 84:E414-9. doi: 10.1093/neuros/nyy324

18. Al-Waili NS, Butler GJ, Beale J, Hamilton RW, Lee BY, Lucas P. Hyperbaric oxygen and malignancies: a potential role in radiotherapy, chemotherapy, tumor surgery and phototherapy. Med Sci Monit. (2005) 11:RA27989. Available online at: https://www.medscimonit.com/abstract/index/idArt/ 428463

19. Maier P, Hartmann L, Wenz F, Herskind C. Cellular pathways in response to ionizing radiation and their targetability for tumor radiosensitization. Int $J$ Mol Sci. (2016) 17:E102. doi: 10.3390/ijms17010102

20. Robertson CA, Evans DH, Abrahamse H. Photodynamic therapy (PDT): a short review on cellular mechanisms and cancer research applications for PDT. J Photochem Photobiol B. (2009) 96:1-8. doi: 10.1016/j.jphotobiol.2009.04.001

21. Zhang X, Guo M, Shen L, Hu S. Combination of photodynamic therapy and temozolomide on glioma in a rat C6 glioma model. Photodiagnosis Photodyn Ther. (2014) 11:603-12. doi: 10.1016/j.pdpdt.2014.10.007

22. de Paula LB, Primo FL, Tedesco AC. Nanomedicine associated with photodynamic therapy for glioblastoma treatment. Biophys Rev. (2017) 9:76173. doi: 10.1007/s12551-017-0293-3

23. Allison RR, Sibata $\mathrm{CH}$. Oncologic photodynamic therapy photosensitizers: a clinical review. Photodiagnosis Photodyn Ther. (2010) 7:61-75. doi: 10.1016/j.pdpdt.2010.02.001
24. Wang S, Bromley E, Xu L, Chen JC, Keltner L. Talaporfin sodium. Expert Opin Pharmacother. (2010) 11:133-40. doi: 10.1517/14656560903463893

25. Stepp H, Stummer W. 5-ALA in the management of malignant glioma. Lasers Surg Med. (2018) 50:399-419. doi: 10.1002/lsm.22933

26. Lakomkin N, Hadjipanayis CG. Fluorescence-guided surgery for high-grade gliomas. J Surg Oncol. (2018) 118:356-61. doi: 10.1002/jso.25154

27. Ewelt C, Nemes A, Senner V, Wölfer J, Brokinkel B, Stummer W, et al. Fluorescence in neurosurgery: its diagnostic and therapeutic use. Review of the literature. J Photochem Photobiol B Biol. (2015) 148:302-9. doi: 10.1016/j.jphotobiol.2015.05.002

28. Kawai N, Hirohashi Y, Ebihara Y, Saito T, Murai A, Saito T, et al. ABCG2 expression is related to low 5-ALA photodynamic diagnosis (PDD) efficacy and cancer stem cell phenotype, and suppression of ABCG2 improves the efficacy of PDD. PLoS ONE. (2019) 14:e0216503. doi: 10.1371/journal.pone. 0216503

29. Hirschberg H, Uzal FA, Chighvinadze D, Zhang MJ, Peng Q, Madsen SJ. Disruption of the blood-brain barrier following ALA-mediated photodynamic therapy. Lasers Surg Med. (2008) 40:535-42. doi: 10.1002/lsm.20670

30. Lawrence JE, Steele CJ, Rovin RA, Belton RJ, Winn RJ. Dexamethasone alone and in combination with desipramine, phenytoin, valproic acid or levetiracetam interferes with 5-ALA -mediated PpIX production and cellular retention in glioblastoma cells. J Neurooncol. (2016) 127:15-21. doi: $10.1007 / \mathrm{s} 11060-015-2012-\mathrm{x}$

31. Origitano TC, Karesh SM, Henkin RE, Halama JR, Reichman OH. Photodynamic therapy for intracranial neoplasms: investigations of photosensitizer uptake and distribution using indium-111 Photofrin-II single photon emission computed tomography scans in humans with intracranial neoplasms. Neurosurgery. (1993) 32:357-63; discussion 363-4. doi: 10.1227/00006123-199303000-00004

32. Kast RE, Skuli N, Sardi I, Capanni F, Hessling M, Frosina G, et al. Augmentation of 5 -aminolevulinic acid treatment of glioblastoma by adding ciprofloxacin, deferiprone, 5-fluorouracil and febuxostat: the CAALA regimen. Brain Sci. (2018) 8:E203. doi: 10.3390/brainsci8120203

33. Silbergeld DL, Chicoine MR. Isolation and characterization of human malignant glioma cells from histologically normal brain. J Neurosurg. (1997) 86:525-31. doi: 10.3171/jns.1997.86.3.0525

34. Baran TM, Foster TH. Comparison of flat cleaved and cylindrical diffusing fibers as treatment sources for interstitial photodynamic therapy. Med Phys. (2014) 41:1-8. doi: 10.1118/1.4862078

35. Johansson A, Palte G, Schnell O, Tonn JC, Herms J, Stepp H. 5aminolevulinic acid-induced protoporphyrin IX levels in tissue of human malignant brain tumors. Photochem Photobiol. (2010) 86:1373-8. doi: 10.1111/j.1751-1097.2010.00799.x

36. Johansson A, Faber F, Kniebühler G, Stepp H, Sroka R, Egensperger R, et al. Protoporphyrin IX fluorescence and photobleaching during interstitial photodynamic therapy of malignant gliomas for early treatment prognosis. Lasers Surg Med. (2013) 45:225-34. doi: 10.1002/lsm.22126

37. Beck TJ, Kreth FW, Beyer W, Mehrkens JH, Obermeier A, Stepp H, et al. Interstitial photodynamic therapy of nonresectable malignant glioma recurrences using 5-aminolevulinic acid induced protoporphyrin IX. Lasers Surg Med. (2007) 39:386-93. doi: 10.1002/lsm.20507

38. Eljamel MS. Photodynamic assisted surgical resection and treatment of malignant brain tumours technique, technology and clinical application. Photodiagnosis Photodyn Ther. (2004) 1:93-8. doi: 10.1016/S1572-1000(04)00014-6

39. Eljamel MS, Goodman C, Moseley H. ALA and Photofrin ${ }^{\circledR}$ fluorescenceguided resection and repetitive PDT in glioblastoma multiforme: a single centre phase III randomised controlled trial. Lasers Med Sci. (2008) 23:361-7. doi: $10.1007 /$ s10103-007-0494-2

40. Eljamel S. Photodynamic applications in brain tumors: a comprehensive review of the literature. Photodiagnosis Photodyn Ther. (2010) 7:76-85. doi: 10.1016/j.pdpdt.2010.02.002

41. Akimoto J, Haraoka J, Aizawa K. Preliminary clinical report on safety and efficacy of photodynamic therapy using talaporfin sodium for malignant gliomas. Photodiagnosis Photodyn Ther. (2012) 9:91-9. doi: 10.1016/j.pdpdt.2012.01.001

42. Kaye AH, Morstyn G, Brownbill D. Adjuvant high-dose photoradiation therapy in the treatment of cerebral glioma: a phase 1-2 study. J Neurosurg. (1987) 67:500-5. doi: 10.3171/jns.1987.67.4.0500 
43. Kostron H, Fritsch E, Grunert V. Photodynamic therapy of malignant brain tumours: a phase I/II trial. Br J Neurosurg. (1988) 2:241-8. doi: $10.3109 / 02688698808992675$

44. Kostron H, Fiegele T, Akatuna E. Combination of FOSCAN ${ }^{\circledR}$ mediated fluorescence guided resection and photodynamic treatment as new therapeutic concept for malignant brain tumors. Med Laser Appl. (2006) 21:285-90. doi: 10.1016/j.mla.2006.08.001

45. McCulloch GA, Forbes IJ, See KL, Cowled PA, Jacka FJ, Ward AD. Phototherapy in malignant brain tumors. Prog Clin Biol Res. (1984). 170:709-17.

46. Muller PJ, Wilson BC. Photodynamic therapy of malignant primary brain tumours: clinical effects, post-operative ICP, and light penetration of the brain. Photochem Photobiol. (1987) 46:929-35. doi: 10.1111/j.1751-1097.1987.tb04871.x

47. Muller PJ, Wilson BC. Photodynamic therapy for recurrent supratentorial gliomas. Semin Surg Oncol. (1995) 11:346-54. doi: 10.1002/ssu.2980110504

48. Muller PJ, Wilson BC. Photodynamic therapy of brain tumors-a work in progress. Lasers Surg Med. (2006) 38:384-9. doi: 10.1002/lsm.20338

49. Muller PJ, Wilson BC. Photodynamic therapy of supratentorial gliomas. In: Proceedings of SPIE 2972, Optical Methods for Tumor Treatment and Detection: Mechanisms and Techniques in Photodynamic Therapy VI, 8 May 1997 (San Jose, CA) (1997). doi: 10.1117/12.273505

50. Muller PJ, Wilson BC, Lilge LD, Yang VX, Hetzel FW, Chen Q, et al. Photofrin photodynamic therapy for malignant brain tumors. Opt Methods Tumor Treat Detect Mech Tech Photodyn Ther X. (2001) 4248:34. doi: 10.1117/12.424454

51. Muragaki Y, Akimoto J, Maruyama T, Iseki H, Ikuta S, Nitta M, et al. Phase II clinical study on intraoperative photodynamic therapy with talaporfin sodium and semiconductor laser in patients with malignant brain tumors. J Neurosurg. (2013) 119:845-52. doi: 10.3171/2013.7.JNS13415

52. Nitta M, Muragaki Y, Maruyama T, Iseki H, Komori T, Ikuta S, et al. Role of photodynamic therapy using talaporfin sodium and a semiconductor laser in patients with newly diagnosed glioblastoma. J Neurosurg. (2018) 1-8. doi: 10.3171/2018.7.JNS18422. [Epub ahead of print].

53. Popovic EA, Kaye AH, Hill JS. Photodynamic therapy of brain tumors. Semin Surg Oncol. (1995) 11:335-45. doi: 10.1002/ssu.2980110503

54. Powers SK, Cush SS, Walstad DL, Kwock L. Stereotactic intratumoral photodynamic therapy for recurrent malignant brain tumors. Neurosurgery. (1991) 29:688-95; discussion: 695-6. doi: 10.1097/00006123-199111000-00008

55. Rosenthal MA, Kavar B, Uren S, Kaye AH. Promising survival in patients with high-grade gliomas following therapy with a novel boronated porphyrin. $J$ Clin Neurosci. (2003) 10:425-7. doi: 10.1016/S0967-5868(03)00062-6

56. Schwartz C, Ruhm A, Tonn J-C, Kreth S, Kreth F-W. Interstital photodynamic therapy of de-novo glioblastoma multiforme WHO IV. Neurooncology. (2015) 17:v214-20. doi: 10.1093/neuonc/nov235.25

57. Stylli SS, Howes M, MacGregor L, Rajendra P, Kaye AH. Photodynamic therapy of brain tumours: Evaluation of porphyrin uptake versus clinical outcome. J Clin Neurosci. (2004) 11:584-96. doi: 10.1016/j.jocn.2004.02.001

58. Stylli SS, Kaye AH, MacGregor L, Howes M, Rajendra P. Photodynamic therapy of high grade glioma-long term survival. J Clin Neurosci. (2005) 12:389-98. doi: 10.1016/j.jocn.2005.01.006

59. Vanaclocha V, Sureda M, Azinovic I, Rebollo J, Cañón R, Sapena NS, et al. Photodynamic therapy in the treatment of brain tumours. A feasibility study. Photodiagnosis Photodyn Ther. (2015) 12:422-7. doi: 10.1016/j.pdpdt.2015.05.007

60. Akimoto J, Fukami S, Ichikawa M, Mohamed A, Kohno M. Intraoperative photodiagnosis for malignant glioma using photosensitizer talaporfin sodium. Front Surg. (2019) 6:12. doi: 10.3389/fsurg.2019.00012

61. Akimoto J, Fukami S, Suda T, Ichikawa M, Haraoka R, Kohno M, et al. First autopsy analysis of the efficacy of intra-operative additional photodynamic therapy for patients with glioblastoma. Brain Tumor Pathol. (2019) 36:144-51. doi: 10.1007/s10014-019-00351-0

62. Krishnamurthy S, Powers SK, Witmer P, Brown T. Optimal light dose for interstitial photodynamic therapy in treatment for malignant brain tumors. Lasers Surg Med. (2000) 27:224-34. doi: 10.1002/1096-9101(2000)27:3<224::AID-LSM4>3.0.CO;2-\#

63. Canti G, Lattuada D, Nicolin A, Taroni P, Valentini G, Cubeddu R. Antitumor immunity induced by photodynamic therapy with aluminum disulfonated phthalocyanines and laser light. Anticancer Drugs. (1994) 5:4437. doi: 10.1097/00001813-199408000-00009

64. Krysko DV, Garg AD, Kaczmarek A, Krysko O, Agostinis P, Vandenabeele P. Immunogenic cell death and DAMPs in cancer therapy. Nat Rev Cancer. (2012) 12:860-75. doi: 10.1038/nrc3380

65. Kroemer G, Galluzzi L, Kepp O, Zitvogel L. Immunogenic cell death in cancer therapy. Annu Rev Immunol. (2013) 31:51-72. doi: 10.1146/annurev-immunol-032712-100008

66. Castano AP, Mroz P, Hamblin MR. Photodynamic therapy and anti-tumour immunity. Nat Rev Cancer. (2006) 6:535-45. doi: 10.1038/nrc1894

67. Garg AD, Nowis D, Golab J, Agostinis P. Photodynamic therapy: illuminating the road from cell death towards anti-tumour immunity. Apoptosis. (2010) 15:1050-71. doi: 10.1007/s10495-010-0479-7

68. Yi W, Xu HT, Tian DF, Wu LQ, Zhang SQ, Wang L, et al. Photodynamic therapy mediated by 5 -aminolevulinic acid suppresses gliomas growth by decreasing the microvessels. J Huazhong Univ Sci Technol Med Sci. (2015) 35:259-64. doi: 10.1007/s11596-015-1421-6

69. Shibata S, Shinozaki N, Suganami A, Ikegami S, Kinoshita Y, Hasegawa $\mathrm{R}$, et al. Photo-immune therapy with liposomally formulated phospholipidconjugated indocyanine green induces specific antitumor responses with heat shock protein-70 expression in a glioblastoma model. Oncotarget. (2019) 10:175-83. doi: 10.18632/oncotarget.26544

70. Ganau L, Prisco L, Ligarotti G, Ambu R, Ganau M. Understanding the pathological basis of neurological diseases through diagnostic platforms based on innovations in biomedical engineering: new concepts and theranostics perspectives. Medicines. (2018) 5:22. doi: 10.3390/medicines5010022

71. Ganau M. Tackling gliomas with nanoformulated antineoplastic drugs: suitability of hyaluronic acid nanoparticles. Clin Transl Oncol. (2014) 16:2203. doi: 10.1007/s12094-013-1114-1

72. Ganau M, Syrmos NC, D’Arco F, Ganau L, Chibbaro S, Prisco L, et al. Enhancing contrast agents and radiotracers performance through hyaluronic acid-coating in neuroradiology and nuclear medicine. Hell J Nucl Med. (2017) 20:166-8. doi: 10.1967/s002449910558

73. Huang X, Wu J, He M, Hou X, Wang Y, Cai X, et al. Combined cancer chemo-photodynamic and photothermal therapy based on ICG/PDA/TPZ-loaded nanoparticles. Mol Pharm. (2019) 16:2172-83. doi: 10.1021/acs.molpharmaceut.9b00119

74. Yang Y, Tu J, Yang D, Raymond JL, Roy RA, Zhang D. Photo- and sono-dynamic therapy: a review of mechanisms and considerations for pharmacological agents used in therapy incorporating light and sound. Curr Pharm Des. (2019) 25:401-12. doi: 10.2174/1381612825666190123114107

75. Zhang H, Wang T, Liu H, Ren F, Qiu W, Sun Q, et al. Second nearinfrared photodynamic therapy and chemotherapy of orthotopic malignant glioblastoma with ultra-small $\mathrm{Cu}^{2-}$ : X Se nanoparticles. Nanoscale. (2019) 11:7600-8. doi: 10.1039/c9nr01789e

76. Kruger CA, Abrahamse H. Utilisation of targeted nanoparticle photosensitiser drug delivery systems for the enhancement of photodynamic therapy. Molecules. (2018) 23:E2628. doi: 10.3390/molecules 23102628

77. Tang XL, Wu J, Lin BL, Cui S, Liu HM, Yu RT, et al. Near-infrared lightactivated red-emitting upconverting nanoplatform for T1-weighted magnetic resonance imaging and photodynamic therapy. Acta Biomater. (2018) 74:360 73. doi: 10.1016/j.actbio.2018.05.017

78. Tsai YC, Vijayaraghavan P, Chiang WH, Chen HH, Liu TI, Shen MY, et al. Targeted delivery of functionalized upconversion nanoparticles for externally triggered photothermal/photodynamic therapies of brain glioblastoma. Theranostics. (2018) 8:1435-48. doi: 10.7150/thno.22482

Conflict of Interest: The authors declare that the research was conducted in the absence of any commercial or financial relationships that could be construed as a potential conflict of interest.

Copyright (c) 2020 Cramer and Chen. This is an open-access article distributed under the terms of the Creative Commons Attribution License (CC BY). The use, distribution or reproduction in other forums is permitted, provided the original author(s) and the copyright owner(s) are credited and that the original publication in this journal is cited, in accordance with accepted academic practice. No use, distribution or reproduction is permitted which does not comply with these terms. 